\title{
Implementation Oriented Phase based IRIS Recognition
}

\author{
Jaydeep N. Kale \\ Assistant Professor \\ Computer Department, SRES \\ COE, Kopargaon
}

\author{
Nilesh G. Pardeshi \\ Assistant Professor \\ Computer Department, SRES \\ COE, Kopargaon
}

\author{
Vikas N. Nirgude \\ Assistant Professor \\ Computer Department, SRES \\ COE, Kopargaon
}

\begin{abstract}
Phase based image matching is one of the technique which is used for iris recognition. In this technique phase component present in Two dimensional (2D) Discrete Fourier Transform (DFT) of given images are used to determine similarity between two images. This technique can be used for developing applications such as access control system. But here problem is size of iris database. As number of individuals using such application will go on increasing, size of iris database will also go on increasing. This paper discusses the method which is used to address this problem. In this paper 2D Fourier phase code (2D FPC) is used to represent iris information. Instead of storing whole iris image, only 2D FPC is stored in the database which reduces size of required database significantly. This method is evaluated with CASIA iris image database (version 1.0).
\end{abstract}

\section{General Terms}

Pattern Recognition, Security.

\section{Keywords}

Iris recognition, Biometrics, 2D DFT.

\section{INTRODUCTION}

Today security is important in access to restricted, sensitive areas such as airports where probability of attack by terrorist is more. Security also comes in picture while using credit card as credit card fraud now costs many billion dollars annually. The person identification is also required in applications like passport control, bank automatic teller machines, protected access to premises or assets. So biometrics is important.

The aim of biometrics is to identify individuals using physiological or behavioral characteristics such as fingerprints, face, iris, retina, and palm-prints. Among many biometric techniques, iris recognition is one of the best approach due to its high reliability for personal identification [1], [2], [3], [4]. The human iris, which is the annular part between the pupil and the white sclera, has a complex pattern. The iris pattern is unique to each person and to each eye and is essentially stable over a lifetime. Also iris pattern of left and right eye is different. Uniqueness, stability makes iris recognition a particularly promising solution to security.

Kazuyuki et al developed iris recognition using phase-based image matching [1]. They developed image matching technique using only the phase components in 2D DFT and also presented the method for reducing size of iris database using 2D FPC. But using 2D FPC affects matching scores. Kazuyuki et al have not given any analysis in this direction. So in this paper we are showing how 2D FPC affects matching score. For performing analysis we have used iris images from CASIA iris image database (version 1.0) [5].

This paper is organized as follow. Section 2 introduces the principle of phase based image matching using Phase Only Correlation (POC) function. Section 3 focuses on baseline algorithm which is used for iris matching. Section 4 describes detailed process of reducing size of iris database. Section 5 is related with experimental results obtained for CASIA version 1.0 database.

\section{PHASE BASED IRIS MATCHING ALGORITHM}

This algorithm consists of two stages: 1) the preprocessing stage and 2) matching stage. The preprocessing stage is used to find the iris region in the captured eye image and to produce a normalized iris texture image with a fixed size ( $256 \times 128$ pixels). The preprocessing stage contains following steps:
- $\quad$ IRIS Localization
- $\quad$ IRIS Normalization
- $\quad$ Eyelid Masking
- $\quad$ Contrast Enhancement
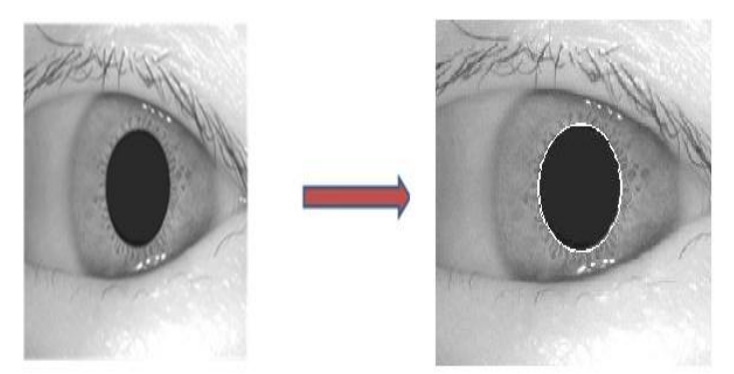

(a)
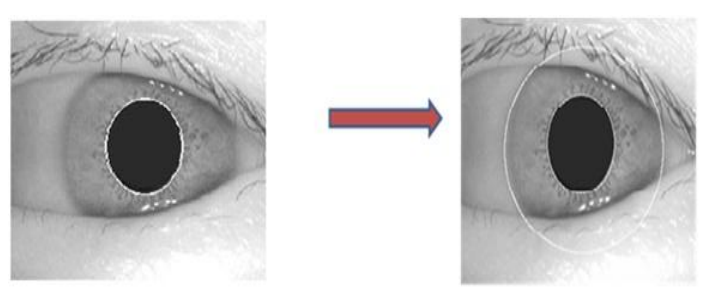

(b)

Fig 1: IRIS Localization (a)Inner boundary detection (b) Outer boundary detection
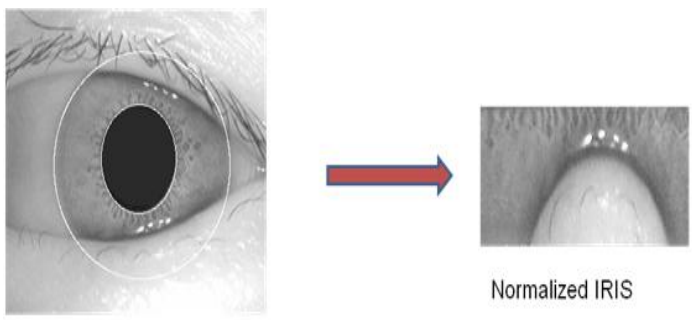

Normalized IRIS

Segmented Eye Image

Fig 2: IRIS Normalization 


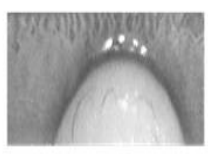

Normalized IRIS

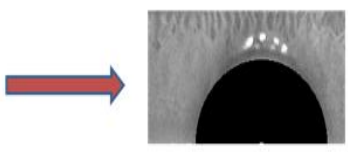

Eyelid Masking
Fig 3: Eyelid Masking

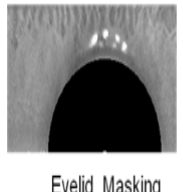

Eyelid Masking

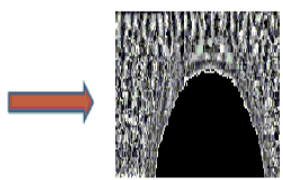

Contrast Enhancement
Fig 4: Contrast Enhancement

IRIS localization contains two steps i.e Inner boundary detection and outer boundary detection as shown in the figure 1. Inner boundary detection step is used to detect inner boundary which is present in between pupil and iris while outer boundary detection step is used to detect outer boundary which is present in between iris and sclera.

The figure 2 shows how normalized iris is produced. Eyelid masking mask the irrelevant eyelid region in the normalized iris image as shown in figure 3 and figure 4 shows Contrast Enhacement step.

In matching stage phase based image matching is used to determine similarity between two iris images.

This section introduces idea of Phase Only Correlation (POC) function [1], [6], [7], [8], [9], [10]. In POC function, only phase components present in 2D DFT of images are used for comparison. Consider two N1 $\times$ N2 images $f(n 1, n 2)$ and $\mathrm{g}(\mathrm{n} 1, \mathrm{n} 2)$, where we assume that the index ranges are $\mathrm{n} 1=-$ $\mathrm{M} 1, \ldots \ldots, \mathrm{M} 1(\mathrm{M} 1>0)$ and $\mathrm{n} 2=-\mathrm{M} 2, \ldots \ldots \ldots, \mathrm{M} 2(\mathrm{M} 2>0)$. Also $\mathrm{N} 1=2 \mathrm{M} 1+1$ and. $\mathrm{N} 2=2 \mathrm{M} 2+1$. Let $\mathrm{F}(\mathrm{k} 1, \mathrm{k} 2)$ and $\mathrm{G}(\mathrm{k} 1, \mathrm{k} 2)$ be the 2D DFTs of the two images. $F(k 1, k 2)$ and $G(k 1, k 2)$ are given by

$$
\begin{aligned}
& \mathrm{F}\left(\mathrm{k}_{1}, \mathrm{k}_{2}\right)=\sum_{\mathrm{n}_{1}=-\mathrm{M}_{1} \mathrm{n}_{2}=-\mathrm{M}_{2}}^{\mathrm{M}_{1}} \sum^{\mathrm{M}_{2}} \mathrm{f}\left(\mathrm{n}_{1}, \mathrm{n}_{2}\right) \mathrm{W}_{\mathrm{N}_{1}}^{\mathrm{k}_{1} \mathrm{n}_{1}} \mathrm{~W}_{\mathrm{N}_{2}}^{\mathrm{k}_{2} \mathrm{n}_{2}} \ldots . . \\
& \mathrm{G}\left(\mathrm{k}_{1}, \mathrm{k}_{2}\right)=\sum_{\mathrm{n}_{1}=-\mathrm{M}_{1}}^{\mathrm{M}_{1}} \sum_{\mathrm{n}_{2}=-\mathrm{M}_{2}}^{\mathrm{M}_{2}} \mathrm{~g}\left(\mathrm{n}_{1}, \mathrm{n}_{2}\right) \mathrm{W}_{\mathrm{N}_{1}}^{\mathrm{k}_{1} \mathrm{n}_{1}} \mathrm{~W}_{\mathrm{N}_{2}}^{\mathrm{k}_{2} \mathrm{n}_{2}} .
\end{aligned}
$$

Where

$$
\begin{aligned}
& \mathrm{N}_{1}=2 \mathrm{M}_{1}+1 \text { and } \mathrm{N}_{2}=2 \mathrm{M}_{2}+1 \\
& \mathrm{~W}_{\mathrm{N}_{1}}=\mathrm{e}^{-\mathrm{j} \frac{2 \pi}{\mathrm{N}_{1}}} \text { and } \mathrm{W}_{\mathrm{N}_{2}}=\mathrm{e}^{-\mathrm{j} \frac{2 \pi}{\mathrm{N}_{2}}}
\end{aligned}
$$

Then we calculate cross phase spectrum $\mathrm{RFG}(\mathrm{k} 1, \mathrm{k} 2)$ as follow-

$$
\mathrm{R}_{\mathrm{FG}}\left(\mathrm{k}_{1}, \mathrm{k}_{2}\right)=\mathrm{e}^{\mathrm{j}\left(\theta_{\mathrm{F}}\left(\mathrm{k}_{1}, \mathrm{k}_{\mathbf{2}}\right)-\theta_{\mathrm{G}}\left(\mathrm{k}_{\mathbf{1}}, \mathrm{k}_{\mathbf{2}}\right)\right)}
$$

Then POC function is given as

$$
\mathrm{r}_{\mathrm{fg}}\left(\mathrm{n}_{1}, \mathrm{n}_{2}\right)=\frac{1}{\mathrm{~N}_{1} \mathrm{~N}_{2}} \sum_{\mathrm{k}_{1}=-\mathrm{M}_{1}}^{\mathrm{M}_{1}} \sum_{\mathrm{k}_{2}=-\mathrm{M}_{2}}^{\mathrm{M}_{2}} \mathrm{R}_{\mathrm{FG}}\left(\mathrm{k}_{1}, \mathrm{k}_{2}\right) \mathrm{W}_{\mathrm{N}_{1}}^{-\mathrm{k}_{1} \mathrm{n}_{1}} \mathrm{~W}_{\mathrm{N}_{2}}^{-\mathrm{k}_{2} \mathrm{n}_{2}}
$$

When two images are similar there POC function $\operatorname{rfg}(\mathrm{n} 1, \mathrm{n} 2)$ gives distinct sharp peak. If two images are not similar, the peak value drops significantly. The height of the peak can be used as a good similarity measure for image matching.

The original POC function $\operatorname{rfg}(\mathrm{n} 1, \mathrm{n} 2)$ emphasizes the highfrequency components, which may have less reliability. This reduces the height of the correlation peak significantly, even if the given two iris images are captured from the same eye. On the other hand, the Band Limited POC (BLPOC) function [1], [7], [8], [9] allows us to evaluate the similarity by using the inherent frequency band of the iris texture. Assume that the ranges of the inherent frequency band of iris texture are given by $\mathrm{k} 1=-\mathrm{K} 1, \ldots \ldots \ldots, \mathrm{K} 1$ and $\mathrm{k} 2=-\mathrm{K} 2, \ldots \ldots \ldots \ldots, \mathrm{K} 2$ where $0 \leq \mathrm{K} 1 \leq \mathrm{M} 1$ and $0 \leq \mathrm{K} 2 \leq \mathrm{M} 2$. Thus, the effective size of frequency spectrum is given by $\mathrm{L} 1=2 \mathrm{~K} 1+1$ and $\mathrm{L} 2=2 \mathrm{~K} 2+1$.

The BLPOC function is defined as

$\mathrm{r}_{\mathrm{fg}}^{\mathrm{K}_{1} \mathrm{~K}_{2}}\left(\mathrm{n}_{1}, \mathrm{n}_{2}\right)=\frac{1}{\mathrm{~L}_{1} \mathrm{~L}_{2}} \sum_{\mathrm{k}_{1}=-\mathrm{K}_{1}}^{\mathrm{K}_{1}} \sum_{\mathrm{k}_{2}=-\mathrm{K}_{2}}^{\mathrm{K}_{2}} \mathrm{R}_{\mathrm{FG}}\left(\mathrm{k}_{1}, \mathrm{k}_{2}\right) \times \mathrm{W}_{\mathrm{L}_{1}}^{-\mathrm{k}_{1} \mathrm{n}_{1}} \mathrm{~W}_{\mathrm{L}_{2}}^{-\mathrm{k}_{2} \mathrm{n}_{2}}$

Where $\mathrm{n}_{1}=-\mathrm{K}_{1}, \ldots \ldots \ldots, \mathrm{K}_{1}$ and $\mathrm{n}_{2}=-\mathrm{K}_{2}, \ldots \ldots \ldots, \mathrm{K}_{2}$.

\section{MATCHING ALGORITHMS}

For matching iris images Baseline algorithm is used [1].

\section{REDUCING SIZE OF IRIS DATABASE}

In order to reduce the size of iris data the 2D FPC is used for representing iris information. The 2D FPC is particularly useful for implementing small iris recognition devices. The 2D FPC corresponds to the quantized version of the phase spectrum of a normalized iris image, which is essential for phase-based iris recognition. Instead of using iris images directly, the system registers 2D FPCs as biometric data. Now we will see how 2D FPC affects size of iris database. Assume that the iris region is normalized into a rectangular image block of $256 * 128$ pixels. Assuming 8-bit (256-level) quantization of pixel value, the total data size of an iris image becomes $256 * 128=32$ Kbytes. On the other hand, the size of the 2D FPC with 4-bit quantization can be reduced to 16 Kbytes by utilizing the symmetry of the phase spectrum. Similarly, the sizes of 2D FPCs with 3-bit, 2-bit, and 1-bit quantization are 8,4 , and 2 Kbytes, respectively. Here we have observed that as we go on changing number of bits of quantization, obtained matching score also go on changing. This analysis is discussed in next section.

\section{EXPERIMENT AND DISCUSSION}

This section describes how 2D FPC affetcs matching scores using CASIA iris image version 1.0 database. This database contains 756 gray-scale eye images 108 unique eyes and 7 different images of each eye. Initially preprocessing stage is performed on two iris images (which belongs to same person) to obtain two normalized iris images. The Baseline algorithm is directly applied on these normalized images to obtain matching score. Then 4 bit quantization is applied on these normalized images and again baseline algorithm is applied on 
these 4 bit quantized images. This process is repeated for 3 bit, 2 bit quantized images. The observed matching scores are shown in table 1.

Table 1. Reported results on CASIA version 1.0

\begin{tabular}{|c|c|c|}
\hline $\begin{array}{c}\text { Type of } \\
\text { registered } \\
\text { biometric data }\end{array}$ & $\begin{array}{c}\text { Size of iris } \\
\text { image }\end{array}$ & Matching score \\
\hline Normalized iris image & $32 \mathrm{~KB}$ & 0.18 \\
\hline $\begin{array}{c}4 \text { bit quantized iris } \\
\text { image }\end{array}$ & $16 \mathrm{~KB}$ & 0.17 \\
\hline $\begin{array}{c}3 \text { bit quantized iris } \\
\text { image }\end{array}$ & $8 \mathrm{~KB}$ & 0.169 \\
\hline 2 bit quantized iris \\
image
\end{tabular}

As we can see in table 1 , there is very small change in matching score as we go on reducing number of bits but there is significant change in size of normalized iris image.

These experimental results clearly demonstrate that 2D FPCs are particularly useful for implementing compact iris recognition devices using the DSP technology.

\section{CONCLUSION AND FUTURE SCOPE}

The major contribution of this paper can be summarized as follow:

An implementation-oriented approach for phase based iris recognition is proposed in Section 4. In order to reduce the size of registered iris data and to prevent the visibility of individual iris images, the 2D FPC can be used for representing iris information. The reduction in size of iris does not affect matching scores significantly. Thus the 2D FPC is particularly useful for implementing compact iris recognition devices.

In this paper we used only lower half part of iris in matching algorithm. If we use whole iris region then performance of iris recognition system will definitely increase. The detailed investigation in this direction are left for future study.

\section{ACKNOWLEDGMENT}

Portions of the research in this paper use the CASIA iris image databases (version 1.0) collected by the Institute ofAutomation, Chinese Academy of Science.

\section{REFERENCES}

[1] Kazuyuki Miyazawa, Koichi Ito, Takafumi Aoki, Koji Kobayashi, Hiroshi Nakajima, "An Effective Approach for Iris Recognition Using Phase-Based Image Matching" IEEE Trans. Pattern Analysis and Machine Intelligence, vol. 30, no. 10, Oct. 2008

[2] J.Daugman, "High-Confidence Visual Recognition of Persons by a Test of Statistical Independence," IEEE Trans. Pattern Analysis and Machine Intelligence, vol. 15, no. 11, pp. 1148-1161, Nov. 1993.

[3] L. Ma, T. Tan, Y. Wang, and D. Zhang, "Efficient Iris Recognition by Characterizing Key Local Variations," IEEE Trans. Image Processing, vol. 13, no. 6, pp. 739750 , June 2004

[4] W. Boles and B. Boashash, "A Human Identification Technique Using Images of the Iris and Wavelet Transform,” IEEE Trans. Signal Processing, vol. 46, no. 4, pp. 1185-1188, Apr. 1998.

[5] Iris Image Database, Inst. Automation, Chinese Academy of Sciences, http://www.sinobiometrics.com/,2008.

[6] K. Takita, M.A. Muquit, T. Aoki, and T. Higuchi, "A Sub-Pixel Correspondence Search Technique for Computer Vision Applications," IEICE Trans. Fundamentals, vol. 87-A, no. 8, pp. 1913-1923,Aug. 2004.

[7] K. Ito, H. Nakajima, K. Kobayashi, T. Aoki, and T. Higuchi, "A Fingerprint Matching Algorithm Using Phase-Only Correlation," IEICE Trans. Fundamentals, vol. 87-A, no. 3, pp. 682-691, Mar. 2004.

[8] K. Ito, A. Morita, T. Aoki, T. Higuchi, H. Nakajima, and K. Kobayashi, "A Fingerprint Recognition Algorithm Using Phase- Based Image Matching for Low-Quality Fingerprints," Proc. 12 $2^{\text {th }}$ IEEE Int'l Conf. Image Processing, vol. 2, pp. 33-36, Sept. 2005.

[9] K. Ito, A. Morita, T. Aoki, T. Higuchi, H. Nakajima, and K. Kobayashi, "A Fingerprint Recognition Algorithm Combining Phase-Based Image Matching and FeatureBased Matching," Advances in Biometrics, vol. 3832, pp. 316-325, Jan. 2006.

[10] H. Nakajima, K. Kobayashi, M. Morikawa, A. Katsumata, K. Ito, T. Aoki, and T. Higuchi, "Fast and Robust Fingerprint Identification Algorithm and Its Application to Residential Access Controller," Advances in Biometrics, vol. 3832, pp. 326-333, Jan. 2006. 